\title{
Model of Adolescent Reproductive Health Information Dissemination in Bandung Indonesia
}

\author{
Nuning Kurniasih \\ Faculty of Communication Science \\ Universitas Padjadjaran \\ Bandung, Indonesia \\ nuning.kurniasih@unpad.ac.id
}

\begin{abstract}
During adolescence period, an adolescent undergoes physical, intellectual, emotional and psychological growth. An adolescent also experiences a social environment growth during that period. Out of all the problems regarding adolescent changes, the curiosity towards reproductive issue is enormous since during this period their reproductive organs already able to function as it should be. This study aims to create a model for reproductive health information dissemination thus adolescent will be able to find the proper reproductive health information. This is a qualitative study based on case study approach. The data collection incorporates observation, focus group discussion, interviews with the students of Library and Information Science Program Faculty of Communication Science Universitas Padjadjaran Bandung Indonesia class 2015 and literature study. Triangulation incorporates sources triangulation and theory triangulation. The results show adolescent in Bandung prefer to seek for reproductive health information through their significant others, such as mothers for female adolescent and friends for male adolescent. The model of reproductive health information dissemination in Bandung needs to involve parents and youth organizations or communities as the government representative to deliver information and government programs properly. This study may contribute in disseminating the reproductive health information for adolescent effectively.
\end{abstract}

Keywords-Adolescent; Reproductive Health Information; Information Dissemination Model

\section{INTRODUCTION}

Adolescence is the transition period from a child into an adult. There are three categorizes of adolescence that is early adolescence (ages of 11 to 14), middle adolescence (ages of 15 to 17) and late adolescence (ages of 18 to 21) [1]. During adolescence period, an adolescent undergoes physical, intellectual, emotional and psychological growth. An adolescent also experiences a social environment growth during that period. During the growth times, there is a moment when a child does not like to be treated as a kid. A child persists on having freedom in attitude. When a child has an urgency to be independent from his parents, physical and motor changes, a child always wants to be the center of attention, and has huge curiosity. Out of all the problems regarding adolescent changes, the curiosity towards reproductive issue is enormous since during this period their reproductive organs already able to function as it should be. In
2014, I found the model of adolescent's health information seeking behavior, which including eight stages as seen in Figure 1 below:

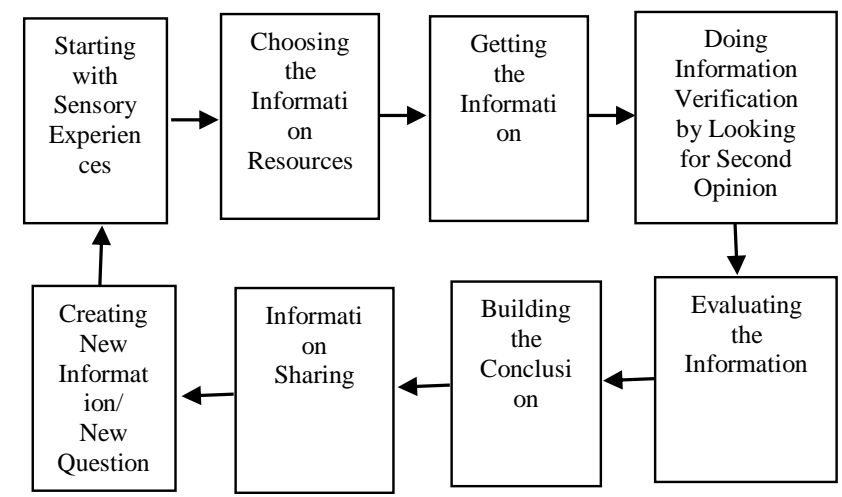

Figure 1 Adolescent Reproductive Health Information Seeking Behavior Model By Nuning Kurniasih [2]

As seen on Figure 1, adolescents start to seek for reproductive health information when they encounter one, such as when a girl has her first period or when a boy has his first wet dream. In order to get the information needed, adolescents - both girls and boys - tend to choose the closer information sources from their surroundings, whether from the family, friends, school (such as teacher), or even the internet. As for the girls, they tend to be more close to their mothers and teachers, while the boys tend to be more close to their friends, teacher and the internet. To verify the information, adolescents will seek for the same information from different sources. When the information is alike then they assume it as the correct information then they will share the information to their friends and colleagues. During this sharing process they might come up with new knowledge or even new questions [2].

Considering that most of the adolescents choose personal blog on the internet as their main reference, thus the information sources from the informal sources without any basic knowledge needs to be concerned. In order to get more insights regarding adolescent's information behavior I conducted the same study in 2017 with different research object. While in previous study (2014) the research objects were junior high school students - categorized in middle 
adolescence, this current study's objects are the students of Library and Information Science Program Faculty of Communication Science Universitas Padjadjaran - categorized in late adolescence. From pre-survey of this study, it was known that college students have knowledge regarding what reproductive health is, although the knowledge is not comprehensive yet. They depend on the informal sources as their main source to seek information needed.

\section{RESEARCH PURPOSES}

This study aims to generate a model of reproductive health information dissemination. It expects that adolescents can find the proper health information on adolescent reproductive; thus, the information might not harm them. The research questions include college students' knowledge about reproductive health, the media used by college students to seek reproductive health information, and the model of reproductive health information dissemination for adolescent in Bandung. This study might contribute in disseminating the reproductive health information for adolescent effectively.

\section{RESEARCH METHOD}

This is a qualitative study based on case study approach. Case study enables researcher to develop the audit trace by analyzing collected data to the conclusion [3]. On 2014, we gained data by conducting knowledge mapping on reproductive health information of senior high school students in Bandung, West Java. The data collected on 2014 is used as the basic of this current study. The data collection incorporates observation, focus group discussion, literature study and interviews with the students of Library and Information Science Program Faculty of Communication Science Universitas Padjadjaran Bandung Indonesia class 2015. Focus Group Discussion (FGD) was conducted with 120 students, while the interviews were conducted to several students who have interesting statements during the FGD session. College students are in their late adolescence, while senior high school students are in their middle adolescence where both of them have distinct characteristics. Triangulation incorporates sources triangulation, which includes re-checking interviews data with two experts from Health Department of Bandung and theory triangulation by doing literature study. According to Yin [4], replication is possible to be claimed when two or more cases support the same theory. Data analysis done in three stages that is describing experiences, describing meanings, and focusing on the analysis [5].

\section{RESULTS AND DISCUSSION}

\section{A. College Students' Knowledge of Reproductive Health}

According to the students of Library and Information Science Program Faculty of Communication Science during the FGD session, reproductive health includes several issues, they are: 1 . the way of human preserve their descendants; 2 . behavior and mental readiness to utilize reproductive organs properly and deviation of using the organs will occur physical and mental problems; 3 . how to keep clean; 4. avoiding free sex; 5. organs health; 6. genitals hygiene; 7. womb health; 8 . period cycle; 9. wet dream; 10. adam's apple; 11 . voice changes; 12 . cervix cancer; 13 . men fertility; 14. access to gain safe sexual life; 15. dietary habit.

According to United Nations, reproductive health defined as physical, mental, and social growth relate to the reproductive process, function, and system in every stage of life [6]. Reproductive health makes people to have responsible sex life, which is safe and satisfying, able to reproduce, and free to decide when, how, and how often to do it [7]. Therefore, it can be concluded that the students have knowledge regarding reproductive health. However, the knowledge is not comprehensive yet.

\section{B. Reproductive Health Information Sources used by the Students}

The result of interviews and FGD show that the early age of students who have knowledge about reproductive health information is around 11 to 12 years old. Some of the male informants admitted having known about the reproductive organs in-check and the wet dream description when they were still 11 or 12 years old. They asked regarding that matter to their parents, brothers, and teachers. After they experienced the wet dream, the curiosity got bigger. Then they shared the story to their friends and stop asking their parents since they felt ashamed of it. Meanwhile, most of the informants admitted knowing about reproductive health matters during their junior high school period in Biology and Religion Class.

The knowledge they got during that period includes the health and religion aspect of reproductive health. Some of the knowledge gained during that period including the way to keep reproductive organs clean, the reproductive system and function, hormones, physical changes, AIDS, herpes, cervix cancer, maturity degree of male's reproductive organs. Meanwhile maturity degree of female's reproductive organs occurs when they experience period, breasts growth, and the period when women can get pregnant.

At the age of around 12 years old, female students admitted asking their mothers on preventing stomach cramp during period, keeping clean the reproductive organs, getting information on cervix cancer issue, menstrual pads changing routines, white discharge, color different of white discharge and the effects, pregnancy, etc. Meanwhile, male students mostly discuss with their friends and teacher, mostly about wet dream, adam's apple, voice changes, and beard. Some of the adolescent active in an organization, such as Adolescent Counseling Information Center, choose to seek for the reproductive health information on the internet then confirm the information validity to their adviser in the organization. The other informal information source for college students is Instagram. All of the informants agreed that they will re-seek for the information they found before when they encounter or undergo some problems with their reproductive health.

Female students admitted that their main source to get information is their mother and girlfriends, while male students admitted being more open with their friends rather than their parents. Only several students refer to books or other reading sources as their main information source, and 
none of them refer to the doctor or medical personnel as their main information source. They will go to the doctor when they are sick. Thus, Health Department of Bandung has initiated an approach to the parents in order to prepare them for the possible reproductive health problems to their children.

\section{Reproductive Health Information Dissemination Model for Adolescent in Bandung}

Information dissemination is a proactive information service designed to educate and inform focused groups of users, so it requires systematic planning [8]. In order to find an effective model of reproductive health information dissemination we need to do several things: 1. identify the problems; 2. identify information needs; 3 . analyze available information sources and possible information sources accessed by adolescent; 4. generate policy and module; 5 . produce health reproductive information packages needed; 6 . coordinate with all parties to disseminate information; 7. formulate information dissemination strategy by defining and identifying the goal, program, sources, approach, media, place, and time frame;8. choose the proper media and information facilitator; 9. conduct information dissemination; 10. accept feedback from adolescent and related parties including the parents; 10. evaluate and improve the shortcoming. Model of Adolescent Reproductive Health Information Dissemination can be seen in Figure 2.

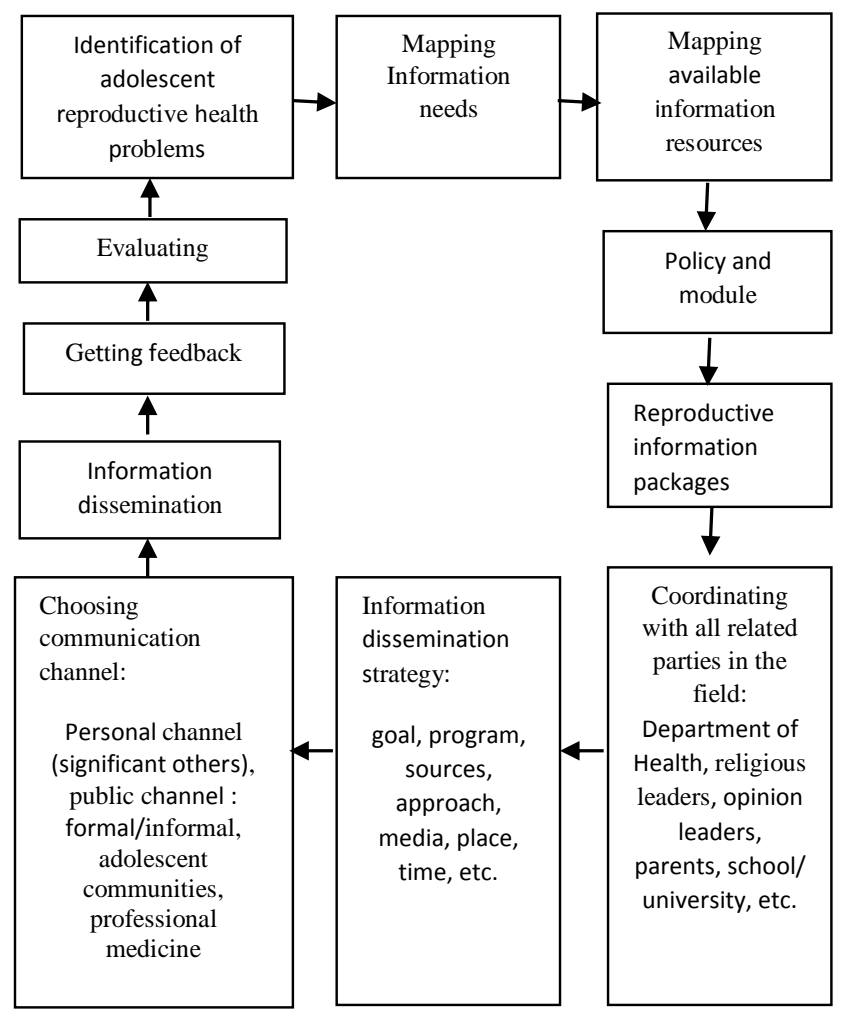

Figure 2 Adolescent Reproductive Health Information Dissemination Model

Department of Health identifies at least seven problems relating to the reproductive function and process, they are, sexually active adolescent even before reach mental and social maturity, adolescent with unwanted pregnancy, adolescent without supportive healthy pregnancy (anemia, lack of energy and calori, etc.), unsafe attempt of abortion by unskilled person, infected by sexually transmitted disease - including infection risk of HIV/AIDS, risk of changing sexual partners, also risk of pregnancy and labor complication including premature baby and other problems [9]. Global Policy Committee of the World Health Organization and WHO account that in order to overcome reproductive health problems, both men and women deserve to get knowledge and have secure, effective, acceptable and accessible access of knowledge, also access to the proper health services [7].

According to the staff of Health Department of Bandung, adolescent most likely to share the information regarding reproductive health with their friends and communities, thus peer group is needed. Information from this peer group is considered being more effective than from other media. Besides, building rapport to adolescent needs more than one access, such as through the school, communities, society, etc. Reproductive health information sources can be delivered through personal channel, public channel or through medical professional health. Personal channel starts from home, both from mother or other close family and friends. Public channel starts from reproductive health information availability in the consultant institution at school or campus, information availability in library, information dissemination through youth organizations, internet access, TV, radio, poster, booklet, leaflet in the public place, etc.

Based on the study results, personal channel is the primary information source for adolescent to look for reproductive health information. Government along with the religious leaders need to approach the parents to prepare them facing the reproductive health problems of their children. It can be followed by approaching youth organization or communities and involve them to be the government representative to disseminate reproductive health information and programs because most adolescent, especially male adolescent, prefer to share knowledge regarding reproductive health with their friends. Government also needs to disseminate reproductive health information through public channel, which placed in visible spots for adolescent.

In Indonesia, reproductive health problems relate to social and religious issues. On one hand, some people do not concern on reproductive health because of social pressure. Since reproductive health considered as taboo, some people worried to be the source of public gossip. On the other hand, as a religious society, reproductive health issues cannot be separated from religion so the role of religious leaders is very important. The Government has made various efforts to increase the adolescents' awareness on their health. For example, Genre program initiated by National Family Planning Board (BKKBN) to help adolescents face the current life problems and plan their future maturely, seminars or counseling about reproductive health in schools initiated by the Department of Health And the National Narcotics Agency, Healthy Living with Friends (HIAT) Program, Training for Teachers , Youth Reproductive Cadre (KRR), Information Center and Counseling for Adolescent Health (PIK-KKR PIKKRR), consultation site for Family Planning Field Officer 
(PLKB), caring counseling vehicles (Kekasih). These programs provide information services of adolescent reproductive health. These programs can be evaluated to determine effective strategies on disseminating adolescent reproductive health information.

\section{CONCLUSION}

Adolescent in Bandung prefer to seek for reproductive health information through their significant others, such as mothers for female adolescent and friends for male adolescent. The model of reproductive health information dissemination in Bandung needs to involve parents and youth organizations or communities as the government representative to deliver information and government programs properly.

\section{ACKNOWLEDGMENT}

This current study is an independent study. While the previous study on 2014, was sponsored by Universitas Padjadjaran.

\section{REFERENCES}

[1] D. E. Greydanus, caring for your teenager: the complete and authoritative guide, New York: Bantam Books, 2003, pp. 1-14.

[2] N. Kurniasih and N. Komariah, "Adolescent reproductive health information seeking behaviour : an information horizon mapping among senior high school students in Bandung city," in the 1st International Conference on Information Science (ICIS) 2015, Shah Alam, 2015.
[3] S. Baškarada, "Qualitative case study guidelines," The Qualitative Report Volume 19, How To Article 24, , pp. 1-18, 2014.

[4] R. K. Yin, Case study research design and methods (5th ed.), Thousand Oaks, CA: Sage, 2014.

[5] D. M. Zucker, "Teaching research methods in the humanities and social sciences how to do case study research," in "how to do case study research?, Amherst, ScholarWorks@UMass Amherst, 2009, p. Chapter 14.

[6] United Nations, "Guidelines on reproductive health," 1 October 2007. [Online]. Available: http://www.un.org/popin/unfpa/taskforce/guide/iatfreph.gdl.html.

[7] L. A. Spielberg, "Introduction to reproductive health \& safe motherhood," in Reproductive Health, Canada, Global Health Education Consortium, 2007.

[8] S. Dhawan, "Basics of information dissimination," in" learning package on Participatory Adult Learning, Documentation and Information Networking (PALDIN) : documentation, dissemination and networking course 02", New Delhi , Group of Adult Education School of Social Sciences Jawaharlal Nehru University, 20xx, pp. 46-58.

[9] A. Imron, Pendidikan kesehatan reproduksi remaja- peer educator \& efektivitas program PIK-KRR di sekolah, Yoyakarta: ArRuzz Media, 2012 .

[10] P. Baxter and S. Jack, "Qualitative case study methodology: study design and implementation for novice researchers," The Qualitative Report Volume 13 Number 4 December, pp. 544-559, 2008.

[11] C. Schell, "The value of the case study as a research strategy," January 1992. [Online]. Available: http://www.financemba.com/Case\%20Method.pdf. [Accessed 7 September 2016].

[12] S. J. Tracy, Qualitative research methods: collecting evidence, crafting analysis, communicating impact, UK: Wiley-Blackwell, 2013. 